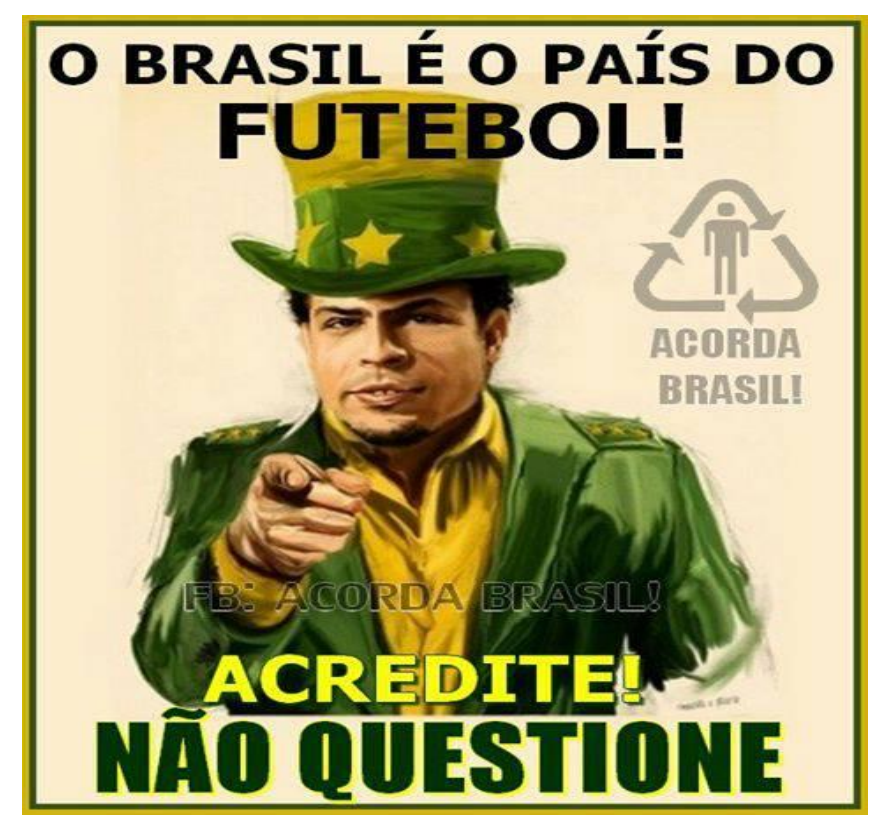

\title{
A pátria (s)em chuteiras: reescritas do Brasil na Copa das Confederações
}

The homeland with(out) cleats: rewriting Brazil in the Confederations Cup

Júlia Almeida $^{1}$

Resumo: Os protestos de junho de 2013 no Brasil constituíram um cenário desafiador para o entendimento dos processos de mudança política, social e cultural em curso no país. Ler os cartazes dessas manifestações como índices de um deslocamento discursivo nos modos de os brasileiros dizerem o país e se dizerem como brasileiros é o intuito deste texto. Tomando como aporte teórico mais amplo as noções de formação discursiva, resistência e contra-discurso de Michel Foucault $(2009 ; 1985)$ e como categoria específica o conceito de aforização de Dominique Maingueneau (2012; 2008b), pretende-se observar como os slogans dos cartazes que circularam pelas ruas e internet nas manifestações retomam, modificam, contradizem outros enunciados que historicamente consolidaram modos hegemônicos de perceber o país e seu povo, deslocando os sentidos mais comumente disponíveis para a formulação e fixação de uma identidade nacional.

Palavras-chave: discurso; manifestações de junho de 2013; copa das confederações; Brasil.

Abstract: The demonstrations of June 2013 in Brazil were a challenging scenario for understanding the processes of political, social and cultural change occurring in the country. The aim of this text is to read the posters of 2013 protests in Brazil as evidence of a discursive shift focusing on how Brazilians say their country and say themselves as Brazilians. Taking as broader theoretical framework the notions of discursive formation, resistance and counterdiscourse of Michel Foucault $(2009 ; 1985)$ and as more specific category the concept of aphorisation of Dominique Maingueneau (2012; 2008b), we intend to observe how slogans that circulated in the streets and on the internet rewrite, modify, contradict other statements that historically consolidated hegemonic ways of perceiving the country and the Brazilians and shift the senses shifting the senses most commonly available for the formulation and establishment of a national identity.

Keywords: discourse; 2013 protests; confederations cup; Brazil.

\footnotetext{
1 Professora da Universidade Federal do Espírito Santo. Email:almeidajulia@terra.com.br Endereço: Universidade Federal do Espírito Santo, Centro de Ciencias Humanas e Naturais. Campus Alaor Queiroz de Araújo Goiabeiras 29060-900 - Vitoria, ES - Brasil
} 
O momento é ainda o das "preliminares" da Copa de 2014, junho de 2013, a Copa das Confederações é iniciada em um fim de semana que sucede uma série de protestos contra o aumento das tarifas de ônibus em São Paulo e Rio de Janeiro, em que a polícia e os governos estaduais e municipais deram mostras de total intolerância e despreparo diante de manifestações políticas, consideradas de imediato pela mídia como baderna e vandalismo. O início da Copa das Confederações, a presença da mídia internacional e a atenção mundial voltada ao evento-teste para a Copa do Mundo Fifa 2014 no Brasil são os fomentadores de um contexto excepcional para que um outro enredo se escreva e surpreenda as expectativas da população, do governo, da Fifa e do mundo: como no supostamente "país do futebol", no espaço-tempo mais propício para o brasileiro reacender a chama sazonal do nacionalismo, inflada pelas numerosas propagandas do governo e das grandes marcas convocando o país a vestir os símbolos do país e vir para a festa, resulta num outro sentimento (de indignação), num modo imprevisto de ocupação das ruas (das grandes manifestações), numa outra discursividade (dos milhares de cartazes em protesto), numa ampla reinvenção dos sentidos que se quer para o país (que mostraremos aqui), numa nova possibilidade de mobilização e exercício da cidadania (via redes sociais, sem aparelhos políticos prévios, apartidário).

Em nosso trajeto de pesquisa das "preliminares" que antecederam a Copa das Confederações (ALMEIDA, 2013a), vários desses fatores que agora se colocam já estavam postos nas leituras que fizemos da recepção aos símbolos oficiais do evento. Vimos que a internet era o suporte privilegiado de reação e deslocamento dos sentidos oficialmente construídos para o país: ao ethos de país vitorioso que a logomarca oficial da Copa pretendia disseminar, um ethos de desolação, de país eticamente intolerável. Também percebemos como uma insatisfação com relação à Copa saiu das telas em setembro de 2012 em alguns protestos contra a presença do boneco da mascote nas grandes capitais, patrocinado e assinado pela Coca-Cola, denunciando a ocupação de praças e espaços públicos, os milhares de remoções e expulsões (ALMEIDA, 2013b). Também neste momento a internet era o ambiente de registro e comentário (em vídeos) desses protestos ainda incipientes contra a gestão da Copa do Mundo, pouco divulgados pela grande mídia, explicitando as contradições do processo de preparação e realização da Copa 2014: seus custos sociais, culturais, materiais etc.

A imersão neste entorno discursivo da Copa de 2014 já apresentava, contraposto ao discurso oficial dos organizadores, do governo e da grande mídia, que pauta o 
processo de construção de uma imagem dominante do país, uma rica produção de narrativas que consideramos contra-discursivas, já que interpelavam os acontecimentos a partir de ângulos de inserção menos favoráveis (os remanejados das áreas de desapropriação, por exemplo) e que imprimiam alguma resistência ao projeto de constituição de um país sem contradições para ser apreciado do exterior. Michel Foucault que, em toda sua obra, articulou discurso e poder, salientou o lugar inelutável dos pontos de resistência nas relações e redes de saber-poder, pensando o discurso como um "jogo complexo e instável” que "veicula e produz poder; reforça-o mas também o mina, expõe, debilita e permite barrá-lo" (1985, p. 96); como discurso e contra-discurso.

Sua noção de formação discursiva, formulada no final da década de sessenta como um sistema de dispersão ou repartição do que pode ser dito, de que se podem definir regularidades entre objetos, tipos de enunciação, conceitos e escolhas temáticas (2009, p. 43) vai sendo reescrita, em anos posteriores, a partir da questão das técnicas de poder e dos discursos que o engendra ou lhe dão suporte (dispositivos de poder-saber), mas também "com o que comporta de deslocamentos e de reutilizações de fórmulas idênticas para objetivos novos" (1985, p. 96).

Pareceu-nos, então, que, para além dos dispositivos de homogeneização de uma visibilidade oficial para o Brasil no contexto da Copa, essas marcas na internet e fora dela produziam deslocamentos nos modos de se narrar o país, mais próximos de uma "dissemiNação", como Hommi Bahbha denomina a confluência de histórias e contranarrativas que escrevem uma nação como “"zona de instabilidade oculta' onde reside o povo" (FANON apud BHABHA, 1990, p. 303, tradução nossa), revolvendo o terreno das manobras ideológicas pelas quais comunidades recebem identidades essencializadas.

Que essa vontade de dar a ver o "lado escuro" da preparação e realização da Copa tenha se somado a outras vontades sociais e se precipitado para as ruas, sobrepujando o efeito catártico do futebol sobre os brasileiros, não deixa de ser algo surpreendente, mesmo diante dessas marcas de insatisfação que colhemos ao longo do último ano. Nesse novo momento de "dissemiNação", em que um espaço de reivindicações se constrói entre as ruas e as redes, salta aos olhos e ouvidos o modo como os brasileiros procuram se reescrever e reescrever o país, numa ampla produção e circulação de slogans e palavras de ordem, que se materializam em cartazes e coros com reverberação na internet (em manifestos, convites, fotos de cartazes etc.) e que se somam a um enorme acervo de iconotextos propriamente digitais: memes, tiras, textos, depoimentos etc. compartilhados no volumoso fluxo que as redes sociais fazem circular. 
Sem falar nas notícias e artigos de opinião que os órgãos de imprensa nacionais e internacionais passaram a disponibilizar ao leitor, a partir do dia 17 de junho, revertendo o estado de silenciamento que parecia querer se instalar pela cobertura limitada do protesto do Comitê Popular da Copa Copa para quem? em Brasília, antes da abertura da Copa das Confederações, que aparecia mais detalhado em notícias internacionais do que na voz dos jornalistas brasileiros, assim como as vaias na abertura do evento durante as falas do Presidente da Fifa, Joseph Blatter, e da Presidente Dilma Roussef, que foram cortadas na edição oficial feita pela TV Globo, transmissora oficial do evento, o que parecia demonstrar que viveríamos um apagamento das formas de protesto que transbordassem o "padrão Fifa" dos grandes eventos.

Tudo isso mudou de um dia para o outro. A impressionante manifestação em todo o país na segunda-feira, dia 17 de junho, convocada pelas redes sociais, e as que se seguiram ao longo da semana, fizeram com que as emissoras de televisão mudassem sua programação para incluir transmissão e comentário ininterruptos das manifestações nos finais da tarde, mudando também o "tom" dos comentários visivelmente contrários da primeira semana de protestos: agora manifestações democráticas, pacíficas, "ordeiras", em que agem pequenos grupos isolados mais violentos de "vândalos", que são exibidos detalhadamente na maior parte do tempo da cobertura jornalística.

O que se pretende analisar desse processo não são as características desses movimentos sociais novos que "saem do facebook" e que levaram milhares de pessoas às ruas em centenas de cidades do país, o que é papel das ciências sociais, mas realizar uma análise dos discursos que os slogans (mas também os memes outros textos da internet) colocam em confronto, especialmente a partir das relações que estes estabalecem com enunciados que se constituíram no país em diversos domínios, das artes às ciências, no sentido de compreender o Brasil como nação, povo, especificidade, identidade, e que o historiador Durval Muniz Albuquerque Jr. (2011), em um viés foucaultiano, trata como dispositivo da nacionalidade ou formação discursiva nacionalpopular. Aproximamos esse dispositivo do que a análise do discurso brasileira compreendeu como discurso fundador, propondo que na relação com a linguagem e com os sentidos constitui-se o que chamamos de identidade nacional (ORLANDI, 1993). Considerando que essa identidade nacional é também resultante de apropriações do "popular" por parte do Estado, é resultante de uma relação política (ORTIZ, 1994), é no esteio dessas iniciativas que se coloca este texto. 
Acreditamos que as manifestações que se sucedem ao longo do mês de junho de 2013 no Brasil colocam fundamentalmente em questão o modo como o Brasil e os brasileiros foram essencializados, revolvendo o repertório de aforismos e frases que se tornaram "verdades" naturalizadas sobre o Brasil ao longo do último século: "o gigante adormecido", “o país do futebol”, “o Brasil não é um país sério", a "pátria de chuteiras”, "o país do futuro" etc. Nossa hipótese é de que esse trabalho discursivo feito por parte da população brasileira nos cartazes, mas também em manifestos e iconotextos em circulação na internet, incide justamente sobre o material discursivo que pretendeu fixar o Brasil e os brasileiros em determinados campos de sentidos; um trabalho coletivo de reapropriação dos enunciados que tem nos subjetivado como brasileiros, em geral subvertendo e desautorizando discursos consolidados (subversão), mas também reafirmando expressões e sentidos atribuídos (captação), conforme as noções de Dominique Maingueneau (2004). É, pois, com relação ao interdiscurso, pensado como "espaço de trocas entre vários discursos convenientemente escolhidos" (MAINGUENEAU, 2008a, p. 20) que nos debruçamos sobre esses enunciados dos cartazes ou slogans.

Segundo Maingueneau (2011, p. 40-41), o slogan, e por extensão o slogan político ou militante, que encontramos nas faixas e cartazes das manifestações, pertencem, assim como os provérbios e as máximas, à classe das aforizações ou das "frases sem texto" que "de maneira constitutiva, existem fora de qualquer texto"; são também aforizações, mas de outra classe, as frases destacadas de um texto nas citações. Segundo o autor, os slogans em manifestações e protestos circulam em grupos transitórios que

[...] a enunciação do slogan tem exatamente por função de unir. Quando acontece uma manifestação que reúne uma população heterogênea em torno de uma questão atual, o slogan não tem outra comunidade-suporte senão o próprio grupo que o está enunciando; A comunidade transitória fabrica uma tesauro conjuntural (os slogans co-presentes no espaço-tempo dessa manifestação) que mistura slogans de circunstância e outros que passam de uma manifestação a outra (MAINGUENEAU, 2008b, p. 105).

Consideramos os slogans dos cartazes como porta de entrada, por excelência, para essa reverberação cultural em processo nos modos de dizer o país. Sondaremos aqui algumas formulações dominantes sobre o país que são reescritas nos slogans dos protestos dando ênfase ao mito do "país do futebol" e ao ethos do brasileiro-torcedor daí resultante. A ocupação pelo cidadão dos espaços físicos e simbólicos do torcedor 
durante a Copa das Confederações é acompanhada por uma tomada de posição em relação aos discursos que fundaram alguns dos modos, hoje canônicos, de perceber e dizer o país, que constituem a nossa memória discursiva do nacional, aquela que "torna possível a toda formação discursiva fazer circular formulações anteriores, já enunciadas" (BRANDÃO, 1998, p. 76), a começar pela formulação do "gigante adormecido".

\section{Reescrevendo o Brasil e os brasileiros}

Sabemos que desde o início de século XX o país habituou-se a traduzir suas dificuldades e contradições quando contrastado com as potências europeias, na fórmula do "gigante adormecido", que "consistia em sublimar as dificuldades do presente e transformar a sensação de inferioridade em um mito de superioridade [...] cujo destino de grandiosidade se cumprirá no futuro" (SEVCENKO, 2003, p. 106). Esse discurso atravessou o século em fórmulas como "o país do futuro", que vimos ser recentemente atestada por Barak Obama quando disse, em visita ao Brasil, que o futuro teria chegado para o "país do futuro", agora com sua economia situada entre as seis maiores potências mundiais e, como dizem alguns analistas internacionais, "invejado" por muitos países desenvolvidos.

A segunda década do século XXI inicia-se, assim, com uma promessa de realização desse mito do gigante adormecido, que a publicidade televisiva recente ajudou a desrecalcar, quando vimos as imagens do gigante de matas e florestas levantarse do solo e andar numa propaganda da marca Johnnie Walker. A realização dos grandes eventos esportivos no país seria assim o momento de coroamento dessas conquistas e consolidação de uma imagem-potência do Brasil, mas também, como chamamos em outro texto, de reatualização de um país-só-imagem, "como visibilidade esvaziada de possibilidades reais de existência" (ALMEIDA, 2013b, p. 119).

Não é pouco que essa grande operação de refundação de uma imagem positiva para o Brasil com grandes eventos e custos (seja a fatura da Copa ou seus custos sociais) tenha sido objeto de crítica no momento preciso em que se pretendia consolidála no imaginário nacional e internacional. E é realmente expressivo que um outro sentido de "o gigante acordou" seja ativado para esse momento na voz dos manifestantes, não como imagem resultante do ranking das economias internacionais ou da publicidade do governo e das grandes marcas, mas como efeito da população nas ruas: "o povo acordou". 
O "gigante", como metáfora oficial do país, que no discurso dominante das elites tantas vezes opôs-se ao povo, considerado o empecilho e não uma potência da nação, nos cartazes e nos coros das manifestações torna-se o povo nas ruas em prol dos seus direitos e de outra relação entre o cidadão e o Estado. Diríamos, nos termos que Possenti (2011, p. 61) usa para retomar a noção de fórmula de Jean Pierre-Faye/Alice Krieg-Planque que a fórmula "transpõe também fronteiras ideológicas, passa de uma formação discursiva a outra(s)". Inúmeros cartazes pactuam com essa vontade de ver e ter essa irrupção da cidadania - "o povo acordado" - de modo permanente e não há muito ganho em reproduzi-los aqui. Mais interessante é perceber como se afirma nesses enunciados um ethos - entendido no sentido antropológico como tom, caráter, disposição, estilo moral e estético de um povo (GEERTZ, 1978) - que se opõe às teses dominantes que circulam de forma mais ou menos fixa na frase "o problema do Brasil é o povo".

\author{
O Brasil é um país SURREAL: \\ tomate é ouro, vinagre é bomba \\ leite é formol, menor é anjo, \\ palmada é crime, cerveja é água, \\ carro é arma, política é piada, \\ povo é problema \\ E PROBLEMA SEMPRE \\ É A SOLUÇÃO
}

A precipitação da população para as ruas e essa enunciação coletiva não deixam de ser um novo acerto de contas com aquela formação discursiva que teve em Louis de Couty, Conde de Gobineau, uma de suas formulações mais contundentes na frase "o Brasil não tem povo", reforçando uma percepção negativa da participação do povo e do desenvolvimento da cidadania no Brasil (CARVALHO, 2011, p. 10). As elites simbólicas no país não raramente corroboraram essa afirmação, muitas vezes com ênfase na rejeição das matrizes étnicas da população: o Brasil "envergonhado do Brasil, em particular do Brasil pobre e do Brasil negro" (CARVALHO, 2011, p. 41). Que nessa formação não se pautam as condições de existência de um povo cidadão (educação, renda, saúde etc.) isso é irrelevante para quem afirma o seu resultado como verdade.

Mas não é sem titubear que o gigante acorda. Alguns, diante das metáforas do "sono" e das incertezas do movimento, parodiam o sonambulismo do gigante apressando um desfecho final. De nossa perspectiva, vemos vir à tona a experimentação de uma potência de cidadania que não se esgota neste episódio. Se alguns sociólogos têm reservas quanto à capacidade de essas grandes manifestações no país e no mundo 
produzirem mudanças políticas imediatas e efetivas, não há dúvidas de que são "uma batalha pela construção de significado", como afirma Castells: "o legado de um movimento social consiste na mudança cultural que produziu com sua ação" (2013, p. 11 e 175, respectivamente). O discurso torna-se, assim, a arena dessas lutas pela construção de sentidos e, como afirma Fairclough, "as práticas discursivas em mutação são um elemento importante na mudança social” (2001, p. 82).

\section{"Não queremos Brasil seleção. Queremos Brasil NAÇÃO!"}

Uma visita ao Portal da Copa, site governo federal brasileiro sobre a Copa Fifa $2014^{2}$, nos introduz ao conjunto de peças promocionais (logomarca, selo comemorativo, vinheta) cujo slogan "a pátria de chuteiras" une-se a uma imagem "de brasileiros em

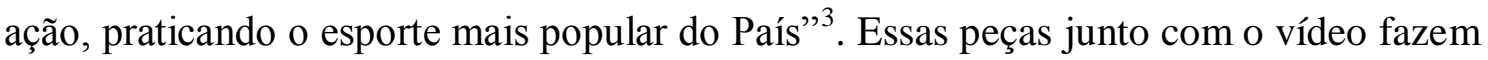
parte da campanha "A pátria de chuteiras", lançada pelo governo federal no final de maio de 2013 e veiculada em canais de televisão, jornais, revistas, internet, mídia internacional e cinema durante todo o mês da Copa das Confederações. O uso da expressão de Nelson Rodrigues é assim justificado:

O uso dessa expressão tem o intuito de posicionar o conteúdo de comunicação do Governo Federal alusivo à temática de futebol, mobilizando os brasileiros para o envolvimento com essa paixão nacional. A intenção ao utilizar a frase é sintetizar a paixão do povo brasileiro pelo futebol: quando a seleção brasileira entra em campo, o país inteiro joga junto ${ }^{4}$.

De fato, Nelson Rodrigues e outros cronistas esportivos tiveram um papel proeminente nessa construção discursiva do Brasil "como país do futebol” ou "pátria em chuteiras", entrelaçando o país e seu futebol, o que configuraria nos termos de Foucault (2009, p. 51 e 53, respectivamente), o "feixe de relações" ou o "conjunto de regras que permitem formá-los como objetos de um discurso", entidades que o discurso constitui e transforma, como vemos aqui: por um lado, afirma-se uma singularidade do futebol brasileiro, um estilo nacional, que exalta traços tidos como tipicamente nacionais, a ginga, o drible e as habilidades individuais; por outro, funde esse futebol considerado nacional (e suas vitórias) com a nação, que passa a ter no futebol um símbolo de suas qualidades e conquistas. Nesse discurso surge, ainda, retomando a

\footnotetext{
${ }^{2}$ Disponível em: <http://www.copa2014.gov.br/>. Acesso em: 24/07/2013.

${ }^{3}$ Disponível em: <http://www.copa2014.gov.br/pt-br/noticia/expressao-a-patria-de-chuteiras-sera-usadacomo-slogan-para-a-copa>. Acesso em: 24/07/2013.

${ }^{4}$ Disponível em: <http://copa2014.gov.br/pt-br/noticia/governo-federal-lanca-a-campanha-a-patria-dechuteiras>. Acesso em: 24/07/2013.
} 
relação entre enunciado e posição de sujeito em Foucault (2009, p. 61 e 59, respectivamente), "um campo de regularidade para diversas posições de subjetividade", que delimita modalidades enunciativas (ou tipos de atividade discursiva), lugares institucionais de legitimação e um "campo perceptivo" de que o sujeito é função: no caso é a posição de torcedor que passa a expressar o caráter nacional, o que leva Nelson Rodrigues a dizer, em 1962, diante de um placar difícil contra a Espanha, que eram "setenta e cinco milhões de brasileiros [que] precisavam mais do gol que todo o Nordeste de água e pão" (BORGES, 2010).

Pesquisadores brasileiros como Ronaldo Helal $^{5}$ vêm apontando a impropriedade de se afirmar hoje o Brasil nos termos do "país do futebol” ou "pátria de chuteiras", uma vez que não haveria mais, nem na crônica esportiva recente nem no campo e na performance dos jogadores, as marcas que caracterizaram o futebol brasileiro como dionisíaco (Gilberto Freyre) e que justificaram a afirmação de uma excepcionalidade brasileira no esporte ao longo da segunda metade do século XX. Outros sociólogos (BARTHOLO et al., 2010), contrapondo-se a uma perspectiva homogeneizante dos discursos em torno do futebol nacional, com base em leitura comparada de crônicas das décadas de 50/60 e atuais, tendem a mostrar que a globalização não significa a ausência do tema do futebol-nação nas crônicas - fomentado pela própria estrutura das competições entre países - que reaparece em meio a embates e contextos eventuais que os exigem.

De um campo de investigação não coincidente com o dos sociólogos e antropólogos do esporte, interessados pela construção social de um modo brasileiro de jogar futebol, voltamos nosso interesse para a formação discursiva que se cristalizou em torno do Brasil como "pátria de chuteiras" na medida em que aciona um dispositivo de produção de sentidos não só sobre o futebol e o estilo nacional de jogo, mas sobretudo sobre o modo de dizer/ver o brasileiro e o Brasil através do futebol. Pelé, representante oficial da Copa de 2014, sintetizou claramente essa perspectiva no contexto dos protestos da Copa das Confederações, quando afirmou: "Vamos esquecer toda essa confusão que está acontecendo no Brasil e vamos pensar que a seleção brasileira é o nosso país [...]"

\footnotetext{
${ }^{5}$ Em conferência apresentada em Recife, na XII Reunião Anual da Associação de Pós-Graduação em Comunicação - Compós (2003), e em Niterói, no III Seminário do Núcleo de Estudos e Pesquisas sobre Esporte e Sociedade - NEPESS (2013).

${ }^{6}$ Disponível em:

<http://internacional.elpais.com/internacional/2013/06/21/actualidad/1371770933_969399.html > Acesso em: $24 / 07 / 2013$.
} 
A seleção deveria ser o objeto privilegiado do país, o que as manifestações contrariam, na medida em que o país, não se ocupando com as questões da seleção, passa a se ocupar com outros problemas do próprio país. Como reverberação de uma formação discursiva que construiu e naturalizou discursos sobre o Brasil e os brasileiros, "a seleção é o país" é um efeito de sentido em relação parafrástica com outros enunciados de uma mesma matriz de sentidos, "na medida em que se concebe esta sequência como pertencente necessariamente a esta ou àquela formação discursiva" (PÊCHEUX; FUCHS, 1990, p.169). São essas e outras paráfrases dessa formação que encontramos como mote de campanhas promocionais atuais do governo federal e ativada na voz de seus representantes.

Justamente quando boa parte da publicidade televisiva das grandes marcas durante a Copa das Confederações convoca a euforia coletiva em torno do futebol, conclamando os brasileiros à ocupação das ruas com a alegria de torcer pela seleção é, neste momento de máxima exploração de uma formação discursiva, que muitos brasileiros vêm subverter o ethos que pesquisadores do esporte gostam de reafirmar como uma verdade inquestionável sobre os brasileiros: basta um gol para que esqueçam todas as contradições do país. Dessa vez, deu-se justamente o contrário e mais surpreendente: o futebol perdeu nesse período esse reiterado efeito de máxima experiência de coesão social (através do lúdico) e o período da Copa das Confederações tornou-se o tempo-espaço de experimentação de uma subjetivação social em busca de outros modos de fazer/dizer o país: à nação coesa em torno da seleção contrapõe-se a "dissemiNação" do país em manifestações e demandas por mudança.

Há, nesse contexto, uma clara rejeição dos slogans dos cartazes ao "Brasilseleção", entendido como país que prioriza o futebol (e outras esferas do lúdico, o carnaval, por exemplo) em detrimento do "Brasil-nação", com qualidade de serviços públicos, como saúde, educação, segurança e saneamento para sua população. Nos termos que José Miguel Wisnik (2008) analisa o Brasil, via psicanálise, diríamos que o país teve um rasgo de princípio de realidade em detrimento do princípio do prazer. Um conjunto de slogans dos cartazes e banners na internet permite ver essa passagem de uma formação a outra; dois deles contestam a afirmação do "país do futebol" na voz de Pelé e Ronaldo, os representantes oficiais da Copa e desse discurso:

Bem-vindos ao Brasil: onde novela, futebol e carnaval é mais importante que educação, saúde e segurança. 
Parabéns, Brasil, conseguimos chamar a atenção do mundo sem bunda, drogas, safadeza ou futebol.

Copa para quem? Prefiro saúde e educação.

Japão, eu troco nosso futebol pela sua educação.

Eu quero: escolas e hospitais no "padrão Fifa"

Era um país muito engraçado,

Não tinha escolas, só tem estádio.

Cartão vermelho para a Copa

Queremos direitos humanos.
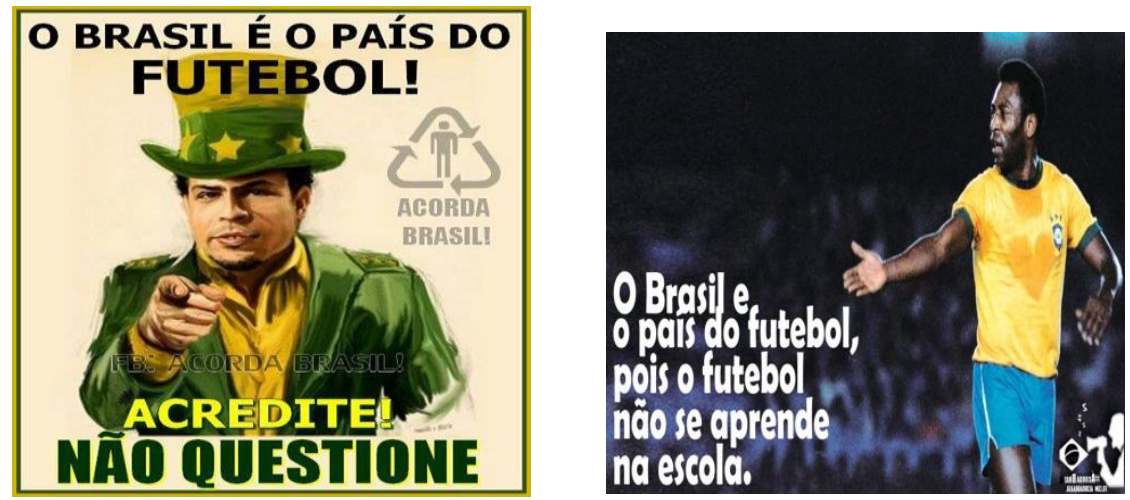

Uma imagem paradoxal do país que salta dos protestos para a análise dos comentadores: “¿Por qué Brasil, siempre orgulloso de su fútbol, parece estar ahora contra el Mundial [...]?” indaga o analista de El País. ${ }^{7}$ A coincidência de agendas da Copa das Confederações e das manifestações, inclusive muitas contra a gestão da Copa, causou grandes surpresas na mídia internacional: quando se imaginaria que os brasileiros para quem "o futebol é uma religião" estariam nas ruas protestando com tanta veemência em dias de Copa e inclusive contra a Copa? Mas, analisando o Manifesto “Copa para quem?", articulado entre a Frente de Resistência Urbana do MTST e os Comitês Populares da Copa, evidencia-se que a rejeição não é ao futebol nem à Copa em si, mas à gestão dos recursos públicos e ao fluxo dos lucros: "nós amamos futebol, vibramos com um gol de nosso time, e gostamos de festejar nas ruas"; no entanto "não somos idiotas e, por isso, não aceitaremos ser manipulados pela "máquina" de lucro da Fifa [...] sustentada por recursos do Estado brasileiro" 8 . O que está em questão é uma rejeição à convocação de um discurso de afirmação da identidade

\footnotetext{
${ }^{7}$ ¿Por qué Brasil y ahora? 17/06/2013.Disponível em: <http://internacional.elpais.com/internacional/2013/06/17/actualidad/1371432413_199966.html> Acesso em: 24/07/2013.

${ }^{8}$ Disponível em: < http://www.mtst.org/index.php/noticias/1102-manifesto-qcopa-pra-quemq.html> Acesso em: 24/07/2013.
} 
nacional associado a uma prática de gestão pública que se volta contra a nação, quando diz adulá-la.

\section{De torcedor a cidadão}

Um dos mais expressivos enunciados que são destacados de um contexto de produção próprio e convida o brasileiro a se reconfigurar no tempo-espaço das manifestações de junho de 2013 é o slogan/refrão da publicidade da Fiat para a Copa das Confederações "Vem prá rua", que se torna palavra de ordem no coro das manifestações e nos cartazes. Destacado do empolgante anúncio publicitário da Fiat para o contexto das manifestações, "Vem prá rua" (por vezes na versão completa "Vem prá rua, porque a rua é a melhor arquibancada do Brasil”) ganha sentido político no quadro das manifestações e passa a convocar a população às ruas, não para torcer e festejar como no anúncio, mas para protestar e lutar pelo país.

No contexto interpretativo das manifestações, de slogan publicitário a slogan político, a aforização contrasta o torcedor-consumidor potencial do anúncio com o atorcidadão. Considerando a noção ampliada de sujeito e sujeição em Foucault a partir de Vigiar e Punir (1987), como função não apenas das restrições e possibilidades discursivas, mas também das sujeições e investimentos sobre o corpo pelas práticas não discursivas, diríamos que se delimitam novas potencialidades discursivas e de ocupação e circulação dos indivíduos nos espaços públicos que são próprias de um sujeito político, para quem o discurso e a rua são os suportes por excelência da ação e transformação das condições de existência. O jingle "Vem prá rua", na voz de Falcão, torna-se o marco desse processo de reapropriação do sentido político da multidão nas ruas, que se contrapõe ao esteriótipo do brasileiro só capaz de encher as ruas na Copa e no carnaval, mas "incapaz" de se mobilizar em torno de direitos e cidadania"

Nesse e em outros casos apresentados, o "novo" enunciado, calcado sobre outro enunciado que ele subverte, permite apreendermos o que Maingueneau afirma como sendo "o relacionamento permanente do discurso e do interdiscurso: este último "trabalha" o discurso, que em retorno o redistribui perpetuamente" (2008b, p. 25). Em muitos casos, rejeita-se a maneira como os brasileiros são representados e "postos em narrativas", para usar a feliz expressão de Alice Krieg-Planque (2011, p. 26), que em muitos casos, como nas peças publicitárias televisivas, mobilizam também dispositivos

\footnotetext{
${ }^{9}$ A reedição do anúncio da Fiat, que passa a ser veiculada depois dos protestos, trazendo à cena manifestantes e não mais torcedores é uma imagem captada desse deslocamento de sentidos do brasileiro que a população nas ruas impõe.
} 
visuais para construção dessas narrativas. Muitos intertextos, revolvendo a memória discursiva do país, ajudam a constituir um "nós-cidadão" que por vezes coloca suas demandas diante de um "outro" hostilizado (os governantes sobretudo, por vezes também a Fifa): "Desculpe o transtorno, estamos mudando o país" subscreve um sujeito que impõe sua presença nos espaços públicos das cidades em prol de mudanças; "Afasta de mim esse cale-se" rejeita a violência passada e presente contra a população“; "Srs. Governantes, cadê o respeito e o fair-play?"devolve aos governantes a frase de Blatter dirigida à população no estádio Mané Garrincha, assim como "Se o mundo pensou que somos um povo sem educação por causa das vaias a Dilma, acertou! Sem educação, sem saúde e, FINALMENTE, sem paciência" recontextualiza o enunciado de Blatter em proveito de uma nova imagem do brasileiro. Em alguns casos mais raros, a aforização não subverte, mas toma a mesma direção de um enunciado que a comunidade partilha (captação), como no verso do hino nacional que circula nos cartazes das manifestações: "verás que um filho teu não foge à luta".

Desse "nós" difuso que os cartazes oferecem um contorno fluido - de manifestantes, cidadãos - saltam imagens dos brasileiros que a mídia nacional e teve dificuldades para processar. Explicar o movimento, conhecer os manifestantes, entender os brasileiros nas ruas foi uma tarefa exigida na pauta de grandes órgãos de imprensa, que aqui e ali se conduziu por caminhos mais ou menos homogeneizantes: "é a nova classe média"10 , são os jovens da "geração virtual", são os "indignados", são "os filhos rebeldes do PT", são "vândalos", etc. Mas a ampliação, consolidação e diversificação das manifestações traem muitas análises apressadas e mantém em suspenso uma palavra única ou final. De novo a "dissemiNação" de Bhabha nos parece um conceito útil para pensar essa não totalização dos fluxos em movimento. Como temos dito, uma confluência de contra-discursos, de contra-sentidos, de contra-usos que reescreve a nação como "zona de instabilidade" e revolve o terreno das estratégias dominantes pelas quais se cristalizam identidades para o país, para os brasileiros e para o próprio movimento em pauta.

Essa intervenção coletiva numa formação discursiva que há muito produz seus efeitos de sentidos e afetos não se esgota nessas poucas frases apresentadas nem garante com elas seus mais duradouros impactos. Mas coloca bem o desconforto com relação ao modo como o discurso hegemônico constitui os brasileiros como "passivos",

\footnotetext{
${ }^{10}$ Evidenciar a presença da classe média nas ruas no sentido de deslegitimar o movimento brasileiro é desconhecer o perfil desses movimentos sociais em rede no mundo alavancados pela internet, em que os jovens com instrução superior têm papel ativo, e também desconsiderar os outros momentos da história das lutas no Brasil, como a ditadura, em que os universitários tiveram importante papel na resistência.
} 
"problema", e o país como "adormecido", "nação-seleção", subvertendo muitas das categorias que pretendem dizer a "alma brasileira": "o novo jeitinho brasileiro" inscrito em um cartaz no meio das manifestações coloca uma interrogação na afirmada identidade brasileira nos termos que muitas formações discursivas incumbidas de entender o Brasil disseram. Por meio desses cartazes e sua inscrição no espaço-tempo da Copa das Confederações, evidencia-se que a preparação da Copa de 2014 trouxe à cena contradições e intoleráveis que parte da sociedade brasileira $(75 \%$ da população apoiando o movimento duas semanas depois de iniciado) não quer mais aceitar.

É digno de nota que, no caso brasileiro, na análise rápida que faz Manuel Castells em seu livro Redes de indignação e esperança (2013, p. 179), esses movimentos sociais em rede tenham como contraponto um governo federal que tem se pautado na "redução da pobreza e de políticas sociais distributivas", dentro de um modelo de crescimento neodesenvolvimentista, que tem suas ambiguidades. Segundo o autor, foi aqui que pela primeira vez na história recente desses movimentos "a mais alta autoridade institucional declarou que tinha a obrigação de escutar a voz das ruas"" (2013, p. 180), reagindo positivamente aos desafios lançados pelo movimento. Curiosamente o slogan do governo federal "País rico é país sem pobreza", que representa um avanço nos modos de dizer/fazer o país foi transformado num cartaz em "País rico é país sem corrupção", que é certamente uma demanda legítima, mas cuja troca confirma o teor positivista que Eni Orlandi apontou nas formações discursivas fundadoras do país, onde se prefere tratar "da questão da malversação do dinheiro público como questão moral (corrupção) e não político-social de distribuição de renda e da justa administração do bem público" (2002, p. 299).

O contra-exemplo (de uma aforização que retroage a discursos mais conservadores) não diminui a extensão da hipótese, que aqui discutimos e exemplificamos, de que se vive um importante momento de reapropriação e reorientação dos sentidos que pretenderam fixar o brasileiro e o Brasil. Reitera o contexto complexo dos extratos discursivos em fricção e a necessidade de aguçarmos nossa percepção para os sentidos em constante deslocamento nos vários embates que o momento apresenta. Se traduzidos e reconciliados pelas instâncias de real horizonte de mudança - tanto na política quanto na sociedade -, as aforizações promissoras permitirão que se amplie e aprofunde a pauta e as ações para que, como dizia José Miguel Wisnik, o futebol não continue a ser o campo de realização daquilo "que a sociedade brasileira sistematicamente não realiza (democracia racial em ato, elevação 
dos pobres à máxima importância [...]" e que "seus dons se irradiem para áreas menos lúdicas" (2008, p. 408); uma perspectiva, enfim, para a pátria sem chuteiras reconciliarse com a pátria em chuteiras.

\section{Referências}

ALMEIDA, Júlia. 2013a. Preliminares iconotextuais da Copa de 2014: o (contra) discurso da logomarca. Contextos Linguísticos, Vitória, v. 8, n. 9, p. 131-146.

. 2013b. Marcas da DissemiNação. Cadernos de Estudos Culturais, v. 5, n. 9, jan/jun, p. 119-128.

ALBUQUERQUE Jr., Durval Muniz. 2011. A invenção do Nordeste e outras artes. 5 ed. São Paulo: Cortez,

BARTHOLO, Tiago Lisboa et al. 2010. A pátria de chuteiras está desaparecendo? Revista Brasileira de Ciências do Esporte, v. 32, n. 1, p. 9-23.

BHABHA, Hommi. (Ed.). 1990. Nation and Narration. New York: Routledge and Keegan Paul.

BORGES, Henrique de Azevêdo. 2013. A pátria em chuteiras. Disponível em: <http://www.univesp.ensinosuperior.sp.gov.br/preunivesp/117/a-p-tria-emchuteiras.html>. Acesso em: 24/07/2013.

BRANDÃO, Helena H. Nagamine. 1998. Introdução à análise do discurso. Campinas: Editora da Unicamp.

CARVALHO, José Murilo de. 2011. Os bestializados: o Rio de Janeiro e a República que não foi. São Paulo: Companhia das Letras.

CASTELLS, Manuel. 2013. Redes de indignação e esperança. Rio de Janeiro: Zahar.

FAIRCLOUGH, Norman. 2001. Discurso e mudança social. Brasília: Editora Universidade de Brasília.

FOUCAULT, Michel. 2009. A arqueologia do saber. Rio de Janeiro: Forense Universitária. 1987. Vigiar e punir. Petrópolis: Vozes. 1985. História da Sexualidade I: a vontade de saber. Rio de Janeiro: Graal. 
GEERTZ, C. A. 1978. A interpretação das culturas. Rio de Janeiro: Zahar, 1978.

KRIEG-PLANQUE, Alice. 2011. "Fórmulas" e "lugares discursivos": propostas para a análise do discurso político. Entrevista. In: MOTTA, Ana Raquel; SALGADO, Luciana (Org.) Fórmulas discursivas. São Paulo: Contexto, p. 11-40.

MAINGUENEAU, Dominique. 2012. Les phrases sans texte. Paris: Armand Colin.

2011. A aforização proverbial e o feminino. In: MOTTA, Ana Raquel; SALGADO, Luciana (Org.) Fórmulas disucrisvas. São Paulo: Contexto, p. 41-58

2008a. Gênese dos discursos. Sâo Paulo: Parábola.

2008b. Cenas da enunciação. Sâo Paulo: Parábola.

2004. Análise de textos da comunicação. São Paulo: Cortez.

ORLANDI, Eni. 2002. Língua e conhecimento linguístico. São Paulo: Cortez.

1993. O Discurso Fundador: a formação de um país e a construção da identidade nacional. Campinas: Pontes.

ORTIZ, R. Cultura brasileira \& identidade nacional. São Paulo: Brasiliense, 1994.

PÊCHEUX, M.; FUCHS, C. 1990. A propósito da análise automática do discurso: atualização e perspectivas. In: GADET, F.; HAK, T. (Org.) Por uma Análise Automática do Discurso. Uma Introdução à Obra de Michel Pêcheux. Campinas: Editora da Unicamp.

POSSENTI, SÍRIO. 2011. Corinthians, jogai por nóis: fórmulas alteradas. In: MOTTA, Ana Raquel; SALGADO, Luciana (Org.) Fórmulas disucrisvas. São Paulo: Contexto, p. 59-67.

SEVCENKO, Nicolau. 2003. Literatura como missão: tensões sociais e criação cultural na Primeira República São Paulo: Companhia das Letras.

WISNIK, José Miguel. 2008. Veneno remédio: o futebol e o Brasil. São Paulo: Companhia das Letras. 
Para citar essa obra:

ALAMEIDA, Julia. Angela C. F. A pátria (s)em chuteiras: reescritas do Brasil na Copa das Confederações. In: RUA [online]. 2014, no. 20. Volume II - ISSN 1413-2109. p. 113-129 Consultada no Portal Labeurb - Revista do Laboratório de Estudos Urbanos do Núcleo de Desenvolvimento da Criatividade.

http://www.labeurb.unicamp.br/rua/

Laboratório de Estudos Urbanos - LABEURB

Núcleo de Desenvolvimento da Criatividade - NUDECRI

Universidade Estadual de Campinas - UNICAMP

http://www.labeurb.unicamp.br/

Endereço:

LABEURB - LABORATÓRIO DE ESTUDOS URBANOS

UNICAMP/COCEN / NUDECRI

CAIXA POSTAL 6166

Campinas/SP - Brasil

CEP 13083-892

Fone/ Fax: (19) 3521-7900

Contato: http://www.labeurb.unicamp.br/contato 